\title{
Conceptus-uterus interactions in pigs: endometrial gene expression in response to estrogens and interferons from conceptuses
}

\author{
G.A. Johnson ${ }^{1,4}$, F.W. Bazer ${ }^{2}$, R.C. Burghardt', T.E. Spencer ${ }^{2}$, \\ G. $\mathrm{Wu}^{2}$ and K.J. Bayless ${ }^{3}$ \\ 'Department of Veterinary Integrative Biosciences, College of Veterinary Medicine and Biomedical \\ Sciences, Texas A\&M University, College Station, TX 77843-4458, USA; ${ }^{2}$ Department of Animal \\ Science, Texas A\&M University, College Station, TX 77843-2471, USA; ${ }^{3}$ Department of Molecular and \\ Cellular Medicine, Texas A\&M Health Science Center, College Station, TX 77843, USA and ${ }^{4}$ Address \\ all correspondence and requests for reprints to: Greg A. Johnson, Department of Veterinary Integrative \\ Biosciences, College of Veterinary Medicine and Biomedical Sciences, Texas A\&M University, College \\ Station, TX 77843-4458, USA
}

\begin{abstract}
This review highlights information on conceptus-uterus interactions in the pig with respect to uterine gene expression in response to estrogens and interferons (IFNs) secreted from elongating conceptuses. Pig conceptuses release estrogens for pregnancy recognition, but also secrete IFNs that do not appear to be antiluteolytic. Estrogens and IFNs induce expression of largely non-overlapping sets of genes, and evidence suggests that pig conceptuses orchestrate essential events of early pregnancy including pregnancy recognition signaling, implantation and secretion of histotroph by precisely controlling temporal and spatial (cell-specific) changes in uterine gene expression through initial secretion of estrogens, followed by cytokines including IFNG and IFND. By Day 12 of pregnancy, estrogens increase the expression of multiple genes in the uterine luminal epithelium including SPP1, STC1, IRF2 and STAT1 that likely have roles for implantation. By Day 15 of pregnancy, IFNs upregulate a large array of IFN responsive genes in the underlying stroma and glandular epithelium including ISG15, IRF1, STAT1, SLAs and B2M that likely have roles in uterine remodeling to support placentation.
\end{abstract}

\section{Introduction}

This review assembles information on the regulation of endometrial gene expression by conceptus estrogens (Geisert et al. 1982a), and interferons (IFNs) delta (IFND) and gamma (IFNG) (La Bonnardière et al. 1991, Lefèvre et al. 1998) during the peri-implantation period of pregnancy. The estrogens and IFNs regulate cell-type specific expression of endometrial genes responsible for the complex interplay between endometrium and conceptus required for pregnancy recognition signaling and implantation.

E-mail: gjohnson@cvm.tamu.edu 


\section{Pig conceptus estrogens and interferons}

Early pregnancy in pigs is complex and is influenced by the overlapping events of conceptus elongation (Fig. 1A), endometrial remodeling for implantation (Fig. 1B) and pregnancy recognition signaling. In pigs, oxytocin released in a pulsatile manner by the uterus binds oxytocin receptors to stimulate pulsatile release of prostaglandin $F_{2 \alpha}$ (PGF) from endometrial luminal epithelium (LE) (Mirando et al. 1995). PGF is the uterine luteolysin in pigs as corpus luteum $(\mathrm{CL})$ regression correlates with pulsatile release of PGF into the uterine venous drainage beginning on Day 15 or 16 of the estrous cycle and hysterectomy extends CL lifespan to about 120 days (Mirando et al. 1995). However, roles of PGs in the pig uterus remain to be clarified. Inhibitors of PG synthesis fail to protect the CL from luteolysis (Kraeling et al. 1985), amounts of PGF and PGE2 in the uterine lumen are greater in pregnant than cyclic pigs (Bazer and Thatcher 1977), uterine PGF is processed into an inactive metabolite through a utero-ovarian countercurrent vascular pathway within the broad ligament (Krzymowski et al. 1990), and PGE2 synthase:PGF synthase ratios are higher in CL from pregnant than cyclic pigs, but not between $\mathrm{CL}$ ipsilateral or contralateral to the pregnant uterine horn. Therefore, it has been suggested that compounds from the conceptus are transported within the mesometrium to the ovaries to enhance CL maintenance (Wasielak et al. 2008).

Pregnancy recognition is the result of conceptus secretion of estrogens on Days 11 and 12 of pregnancy to redirect PGF secretion from the uterine vasculature to the uterine lumen (Fig. 2A \& 2B). The theory of estrogen-induced maternal recognition of pregnancy in pigs is based on the following evidence: (i) the uterine endometrium secretes luteolytic PGF; (ii) pig conceptuses secrete estrogens which are antiluteolytic; (iii) PGF is secreted toward the uterine vasculature (endocrine) in cyclic gilts to induce luteolysis; and (iv) secretion of PGF in pregnant gilts is into the uterine lumen (exocrine) where it is sequestered from the corpora lutea and/or metabolized to prevent luteolysis (Bazer and Thatcher 1977). In addition to pregnancy recognition, conceptus estrogens modulate uterine gene expression thought to be required for implantation (Geisert et al. 1982b). The importance of estrogen to implantation of pig conceptuses is underscored by the fact that premature exposure of the pregnant uterus to estrogen on Days 9 and 10 results in degeneration of all pig conceptuses by Day 15 (Ross et al. 2007). It should be noted that PGE2, as well as lysophosphatic acid (LPA) have proposed roles in pregnancy signaling. Expression of PGE2 synthase by trophoblast and endometrium decreases production of PGF in favor of PGE2 to support CL maintenance (Ziecik et al. 2008). In addition LPA: (i) increases in uterine luminal fluids of pigs; (ii) its receptor, EDG7, is expressed by pig conceptuses; and (iii) its expression is increased by estrogen in endometrial epithelia during early pregnancy (So et al, 2008). Indeed, LPA3 is critical for embryo migration and spacing in mice (Ye et al. 2005), events that are critical to implantation and placentation in pigs.

Pig trophectoderm is unique in secreting both Type I and Type II IFNs during the periimplantation period (Figs. 2A \& 2B). Cultured conceptuses from Day 11 of pregnancy secrete proteins that cross react with antiserum against INF alpha (IFNA) (Cross \& Roberts 1989), but peak antiviral activity is not measured in uterine flushings or conceptus culture media until Day 14 of pregnancy (Mirando et al. 1990). The major IFN species, constituting $75 \%$ of antiviral activity in pig conceptus secretory proteins (CSP), is type II IFNG. The other $(25 \%)$ is the novel type I IFND (La Bonnardière et al. 1991, Lefèvre et al. 1998). Abundant IFNG mRNA is detectable in porcine trophectoderm between Days 13 and 20 of pregnancy, whereas IFND mRNA is detectable in Day 14 conceptuses only by RT-PCR analysis (Joyce et al. 2007a). On Day 15 of pregnancy, immunoreactive IFNG and IFND proteins are co-localized to peri-nuclear membranes typically occupied by endoplasmic reticulum and Golgi apparatus, as well as cytoplasmic vesicles within clusters of trophectoderm cells along the endometrial LE (Lefèvre 
A)

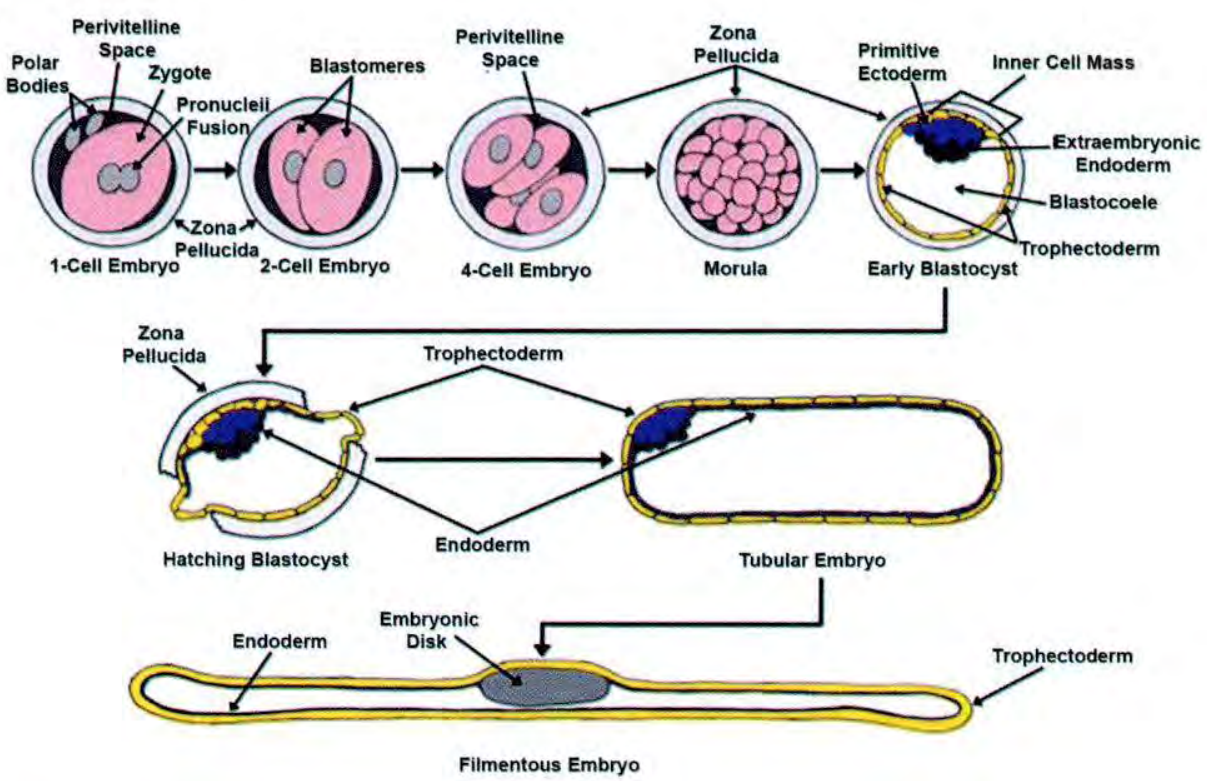

B)

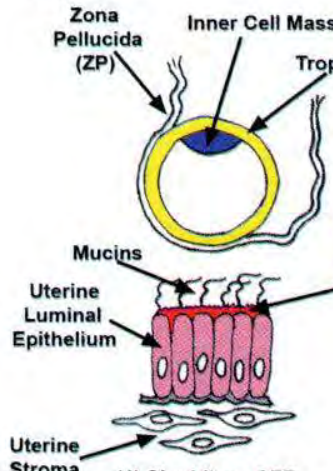

(1) Shedding of ZP
Stroma

rophectoderm

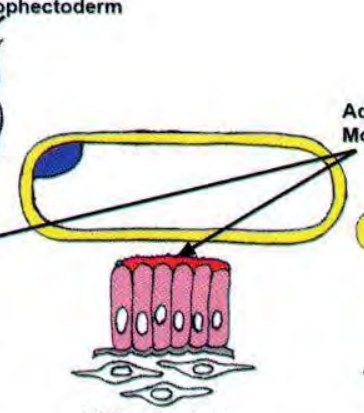

(2) Pre-Contact and Conceptus Orientation

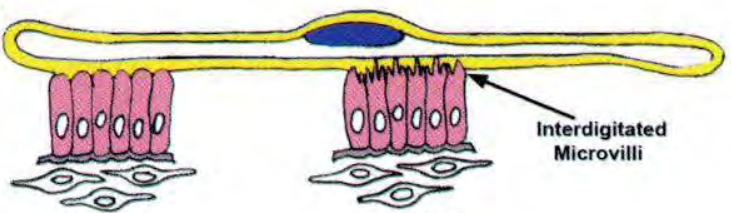

(3) Apposition

(4) Adhesion

Fig. 1 Panel A. Pre-implantation development of the pig conceptus within the oviducts and uterus. The origin and organization of tissue layers within the conceptus are depicted. In pigs, the 1-cell fertilized ovum or zygote undergoes cleavage to form a 2-cell embryo by $26 \mathrm{~h}$ after fertilization, enters the uterus at the 4- to 8-cell stage between 48 to $56 \mathrm{~h}$, differentiates into the blastocyst, "hatches" from the zona pellucida as a 0.5 to $1 \mathrm{~mm}$ diameter sphere, increases in size to Day 10 of pregnancy (2-6 mm), then undergoes a morphological transition to a large sphere of 10 to $15 \mathrm{~mm}$ diameter and then a tubular $(15 \mathrm{~mm}$ by $50 \mathrm{~mm})$ and filamentous $(\mathrm{mm}$ by $100-200 \mathrm{~mm})$ form on Day 11 . Panel B. Implantation Cascade in Pigs. Implantation in pigs extends from Days 13-25 and includes four phases that overlap and involve increasingly complex interactions between trophectoderm and uterine luminal epithelium to achieve true epitheliochorial placentation. Conceptus attachment first requires loss of anti-adhesive molecules in the glycocalyx of LE, comprised largely of mucins that sterically inhibit attachment. This results in "unmasking" of molecules, including selectins and galectins, that contribute to initial attachment of conceptus to uterine LE. These low affinity contacts are then replaced by a more stable and extensive repertoire of adhesive interactions between integrins and maternal ECM, for example secreted phophoprotein 1 (SPP1 or Osteopontin), which appear to be the dominant contributors to stable adhesion at implantation. 
et al. 1998). In contrast to sheep conceptuses, in which a Type I IFN (interferon tau) is the signal for maternal recognition of pregnancy (Spencer et al. 2007), the IFNs produced by pig conceptuses do not appear to be antiluteolytic. Intrauterine infusion of CSP on Days 12 and 15 of the estrous cycle have no effect on interestrus interval or temporal changes in concentrations of progesterone in plasma (Harney \& Bazer 1989). Although pig conceptus IFNs have yet to be shown to influence pregnancy recognition, paracrine effects for IFNs are suggested by localization of IFN receptors on endometrial epithelial cells (Lefèvre et al. 1998), increased secretion of prostaglandin $\mathrm{E}_{2}$ (Harney \& Bazer 1989), expression of several known IFN-responsive genes in the endometrium (Hicks et al. 2003, Joyce et al 2007a, Joyce et al. 2007b, Joyce et al. 2008), and modulation of uterine stromal and glandular epithelial (GE) gene expression by the IFNs in CSP preparations (Joyce et al 2007a, Joyce et al. 2007b, Joyce et al. 2008).

\section{Estrogen- and interferon-stimulated genes in the endometrium}

Estrogens and IFNs regulate endometrial genes that interact to effect communication between endometrium and conceptus during pregnancy recognition and implantation in pigs. Fig. 2 illustrates the fact that timing of estrogen secretion by the conceptus correlates with the induction of SPP1 expression in the LE, whereas stromal induction of STAT1 correlates with IFNG and IFND secretion by the conceptus. Indeed administration of exogenous estradiol to ovariectomized pigs induces SPP1 mRNA in endometrial LE (White et al. 2005), while intrauterine infusion of CSP, which contain IFND and IFNG, into cyclic pigs treated with exogenous estrogen increases STAT1 as compared to intrauterine infusion of control proteins (Joyce et al. 2007a), similar to expression patterns for these genes during the peri-implantation period of pigs (Fig. 2C). Upregulation of SPP1 within uterine LE and STAT1 within stroma and GE in close proximity to the implanting conceptus implies paracrine regulation of genes by conceptus estrogens and IFNs. It is likely that effects of estrogen on the endometrium are restricted to regions near the conceptus due to metabolic activity of trophectoderm. During pregnancy, pig endometrium rapidly converts estradiol to estrone and then converts it to the biologically inactive estrone sulfate which is present in high concentrations within the uterine lumen of pregnant pigs (Flood 1974). The trophectoderm has sulfatase enzyme activity that restores the biological activity of estrogen, allowing for a localized effect of estrogen to up-regulate genes such as SPP1 in LE. In contrast, it is somewhat surprising that initial increases in expression of STAT1 in stroma are restricted to sites of contact between the conceptus and uterus, given that IFNG synthesis and secretion by pig conceptuses appears to be similar in magnitude to IFNT production by sheep conceptuses (Joyce et al. 2007a). Indeed, STAT1 expression increases universally in the stroma and GE of pregnant sheep independently of conceptus location within the lumen, presumably due to the high levels of secretion of IFNT by conceptuses (Spencer et al 2007). One explanation for the spatial pattern of STAT1 expression in the pig uterus is that IFND and IFNG act synergistically to upregulate expression of ISGs. Interactions between Type I and Type II IFNs have been demonstrated previously (Decker et al. 1989). It is plausible that high levels of IFNG act on uterine stroma and GE to increase intracellular stores of interferon-stimulated gene factor 3 (ISGF3) so that the much lower levels of IFND can maximally upregulate STAT1 expression in close proximity to the implanting pig conceptus. To date, only a limited number of estrogen- and IFN-stimulated genes have been localized in the pig endometrium. Table 1 summarizes gene expression in pig uteri during normal pregnancy and in response to i.m. injections of estrogen and/or intra-uterine injections of pig CSP containing IFNG and IFND (Ka et al. 2000, Hicks et al. 2003, White et al. 2005, Joyce et al 2007a, Joyce et al. 2007b, Ka et al. 2007, Ross et al. 2007, Joyce et al. 2008, So et al. 2008, Song et al. 2009). Several of these genes are discussed further in the remainder of this review. 


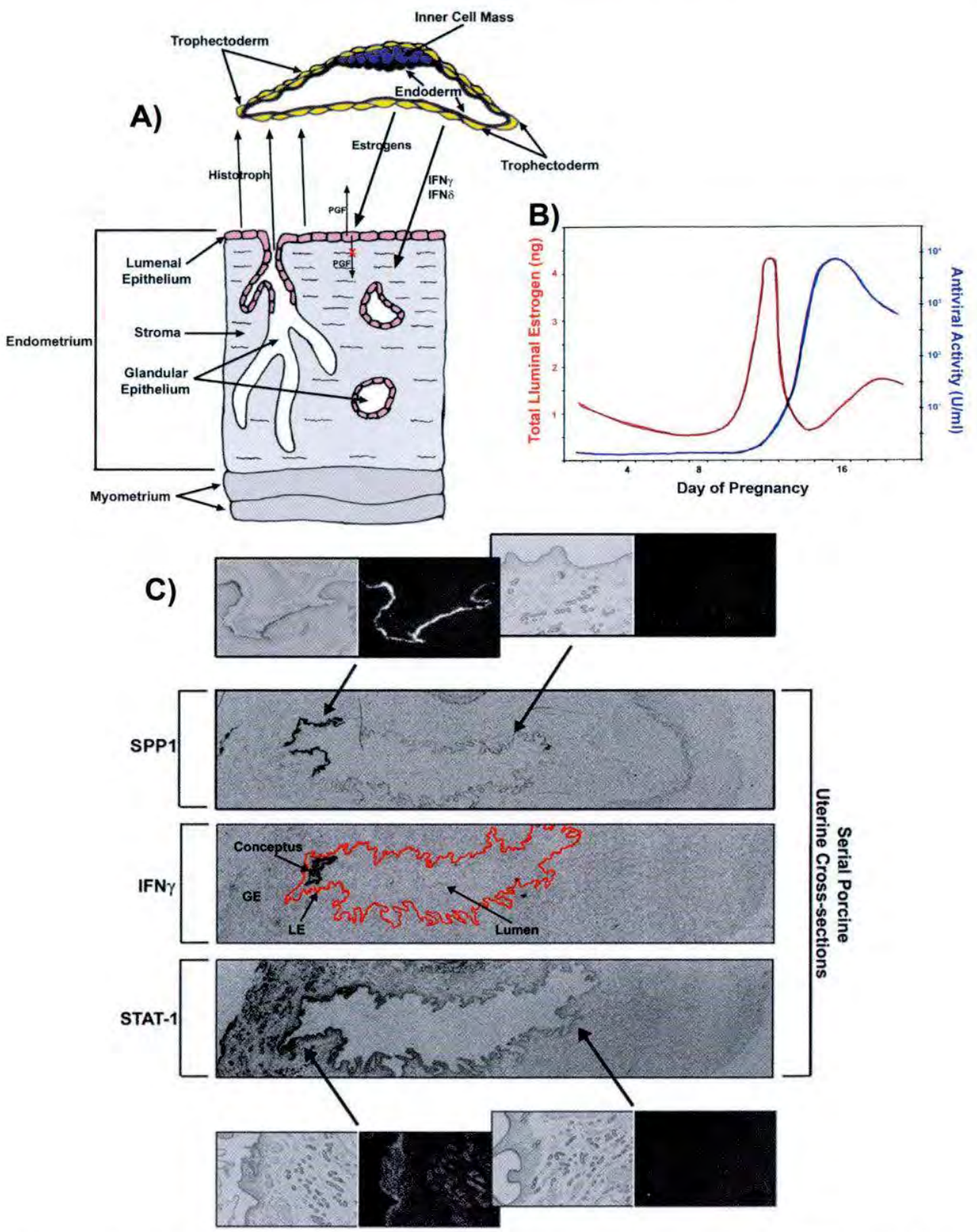

Fig. 2 Panel A. Peri-implantation signaling between the conceptus and uterus in the pig. Secretion of conceptus estrogens and IFNs elicit and support uterine responses including maintenance of the $\mathrm{CL}$, production of histotroph and induction of multiple estrogen- and IFN-stimulated genes. Panel B. Graph depicting temporal changes in uterine luminal levels of conceptus estrogen and IFN antiviral activity in pigs during early pregnancy. Panel C. Conceptus estrogens (E2) induce SPP1 in endometrial luminal epithelium (LE), and conceptus IFNs induce STAT1 in endometrial stroma and glandular epithelium (GE) during the periimplantation period of pig pregnancy. In situ hybridization analysis of SPP1, IFNG and STAT1 mRNAs in autoradiographic images (Biomax-MR; Kodak) showing entire serial cross-sections of the uterine wall from Day 15 of pregnancy. The luminal epithelium of tissue probed for IFNG mRNA has been outlined in red for histological reference. Corresponding brightfield and darkfield images from the same uterus probed with SPP1 and STAT1 cRNAs are also shown. Endometrial SPP1 and STAT1 increase in close proximity to paracrine release of E2 and IFNG from implanting pig conceptuses. Width of each field of autoradiographic images is $20 \mathrm{~mm}$. Width of each field of brightfield and darkfield images is $940 \mu \mathrm{m}$. 
Table 1. Temporal and Cell-Type Specific expression of conceptus estrogen- and interferon-regulated genes during the establishment of pregnancy in pigs. Only genes that have been spatially localized in pig endometrium and trophectoderm are listed.

\begin{tabular}{|c|c|c|c|c|}
\hline \multirow[t]{2}{*}{ Location } & \multicolumn{2}{|c|}{ Regulation } & \multicolumn{2}{|c|}{ Initial Day of Expression } \\
\hline & By Estrogen & By IFNs & $11-13$ & 13-15 \\
\hline Conceptus & & & $\begin{array}{l}\text { Estrogen } \\
\text { EDG7 }\end{array}$ & $\begin{array}{l}\text { IFNG } \\
\text { IFND }\end{array}$ \\
\hline Uterine lumen & $\begin{array}{l}\text { FGF7 } \\
\text { SPP1 } \\
\text { STC1 }\end{array}$ & & $\begin{array}{l}\text { Estrogen } \\
\text { FGF7 } \\
\text { STC1 }\end{array}$ & $\begin{array}{l}\text { IFNG } \\
\text { SPP1 }\end{array}$ \\
\hline LE & $\begin{array}{l}\text { AKR1B1 } \\
\text { B2M } \\
\text { CD24 } \\
\text { FGF7 } \\
\text { IRF2 } \\
\text { MX1 } \\
\text { NMB } \\
\text { SLA1,2,3 } \\
\text { SLA6,7,8 } \\
\text { SPP1 } \\
\text { STC1 } \\
\text { EDG7 }\end{array}$ & & $\begin{array}{l}\text { AKR1B1 } \\
\text { B2M } \\
\text { CD24 } \\
\text { FGF7 } \\
\text { IRF2 } \\
\text { NMB } \\
\text { SLA1,2,3 } \\
\text { SLA6,7,8 } \\
\text { SPP1 } \\
\text { STC1 } \\
\text { EDG7 }\end{array}$ & \\
\hline GE & & $\begin{array}{l}\text { B2M } \\
\text { IRF1 } \\
\text { ISG15 } \\
\text { SLA 1,2,3 } \\
\text { SLA6,7,8 } \\
\text { STAT1 } \\
\text { STAT2 }\end{array}$ & & $\begin{array}{l}\text { B2M } \\
\text { IRF1 } \\
\text { ISG15 } \\
\text { MX1 } \\
\text { SLA1,2,3 } \\
\text { SLA6,7,8 } \\
\text { STAT1 } \\
\text { STAT2 }\end{array}$ \\
\hline ST & & $\begin{array}{l}\text { B2M } \\
\text { IRF1 } \\
\text { ISG15 } \\
\text { SLA 1,2,3 } \\
\text { SLA6,7,8 } \\
\text { STAT1 } \\
\text { STAT2 }\end{array}$ & & $\begin{array}{l}\text { B2M } \\
\text { IRF1 } \\
\text { ISG15 } \\
\text { MX1 } \\
\text { SLA1,2,3 } \\
\text { SLA6,7,8 } \\
\text { STAT1 } \\
\text { STAT2 }\end{array}$ \\
\hline
\end{tabular}

LE, Luminal epithelium; GE, Glandular epithelium; ST, Stroma

Secreted Phosphoprotein 1 (SPP1)

SPP1, also called osteopontin (OPN), is a secreted ECM protein for which expression is upregulated during the initial stages of pregnancy in uteri of pigs (White et al. 2005) and other mammalian species, including humans (Johnson et al. 2003). SPP1 contains an Arg-Gly-Asp (RGD) sequence that mediates binding to cell surface integrin receptors, including $\alpha v \beta 3, \alpha 5 \beta 1$, $\alpha v \beta 1, \alpha v \beta 5$, $\alpha v \beta 6$ and $\alpha 8 \beta 1$ (Johnson et al. 2003). Alternative binding-sequence interactions between SPP1 and integrins such as $\alpha 4 \beta 1, \alpha 9 \beta 1$ and $\alpha 4 \beta 7$ can also occur (Johnson et al. 2003). As noted previously, estrogens secreted by the elongating Day 12 conceptus induce synthesis and secretion of SPP1 specifically in endometrial LE cells in direct apposition to the 
implanting conceptus (White et al. 2005). SPP1 protein is abundant on both the apical surface of uterine LE as well as conceptus trophectoderm ( $\mathrm{Tr}$ ) coinciding with the attachment phase of implantation in pigs (White et al. 2005). Recently, direct binding of $\alpha v \beta 6$ trophectoderm and $\alpha v \beta 3$ uterine LE integrins to SPP1 was demonstrated. This binding stimulated trophectoderm cell adhesion and migration, but not proliferation, suggesting that SPP 1 is an excellent candidate to promote trophectoderm migration for conceptus elongation and attachment to endometrial LE for implantation in pigs (G. Johnson and D. Erikson, unpublished observations).

\section{Stanniocalcin 1 (STC1)}

STC1 is a homodimeric phosphoglycoprotein that regulates calcium and phosphate homeostasis (Wagner et al. 1986, Madsen et al. 1998). STC1 is also expressed in uteri of pregnant pigs, sheep and mice (Stasko et al. 2001, Song et al. 2006, Song et al. 2009). Recently, STC1 mRNA was localized to uterine LE during the period of conceptus attachment to uterine LE for implantation in pigs i.e., Days 12-25 of pregnancy (Song et al. 2008). Further, STC1 expression by uterine LE was induced by progesterone from the CL and further stimulated by estrogen from elongating pig conceptuses (Song et al. 2009). The presence of a $25 \mathrm{kDa}$ form of STC1 in uterine luminal fluids from Days 12 through 15 suggests a role(s) in ion transport within trophectoderm and LE cells (Song et al. 2008). Indeed, total recoverable calcium in uterine flushings from pigs increases abruptly on Days 11 to 12 , coincident with production of estrogen by elongating blastocysts (Geisert et al. 1982a). Therefore, estrogen may induce STC1 secretion from LE that then enhances transport of intracellular calcium to the lumen, resulting in increased levels of free calcium that mediate uterine secretion of multiple proteins that compose histotroph (Geisert et al. 1982b).

\section{Interferon-Stimulated Gene 15 (ISC15)}

In has been known for some time that IFNT increases expression of several IFN-stimulated genes (ISGs) in the stroma of the ruminant uterus. Over the last decade the list of ISGs known to be upregulated in endometrial stroma and GE has grown from one (ISG15 in both cows and sheep) (Johnson et al.1999a, Johnson et al. 1999b), to over 20 proteins (see review for complete listing, Spencer et al. 2007). The first (Naivar et al. 1995) and most thoroughly studied ISG (Rempel et al. 2007) is ISG15, a functional ubiquitin homologue that has the C-terminus LeuArg-Gly-Gly amino acid sequence common to ubiquitin, allowing conjugation to intracellular proteins (Hass et al. 1987). Conjugation of proteins either targets proteins for rapid degradation in the proteasome, or stabilizes proteins for long-term modification (Wilkinson 2000). ISG15 does indeed form stable conjugates with endometrial proteins, indicating a biologically active molecule that is responsive to conceptus IFNs and can target proteins for pregnancy-associated regulation and/or modification (Johnson et al. 1998, Joyce et al. 2005). Shown in Fig. 3 is the first evidence that ISG15 is expressed in the stromal stratum compactum of pregnant pigs in response to conceptus IFNs. ISG15 increases in the stroma between Days 12 and 14, then decreases gradually between Days 15 and 20 to undetectable levels by Day 35 (Data not shown).

Interferon Regulatory Factors (IRFs) 1 and 2

IRF1 is a key intermediate in the induction cascade of many classical ISGs through binding and transactivating IFN-stimulated response elements (ISREs) in their promoters (Floyd-Smith 
A)

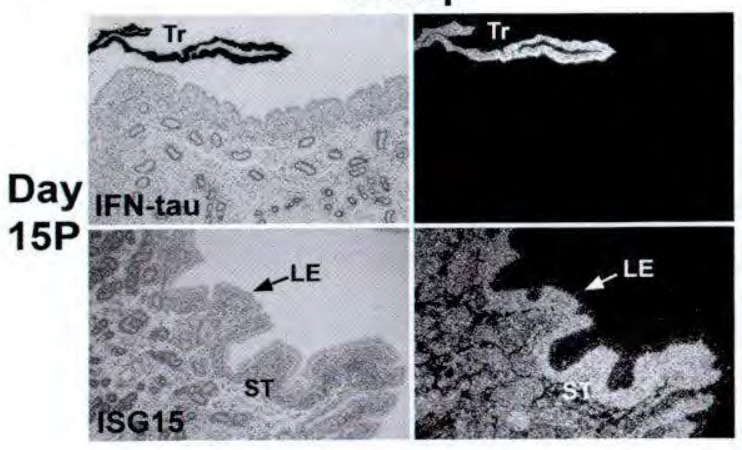

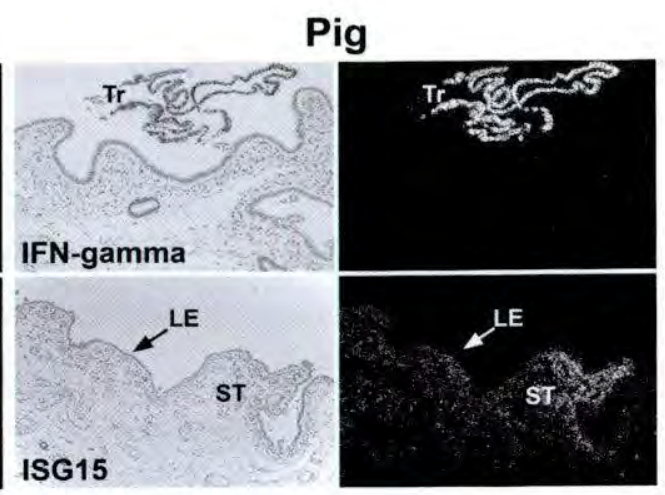

ISG15

B)

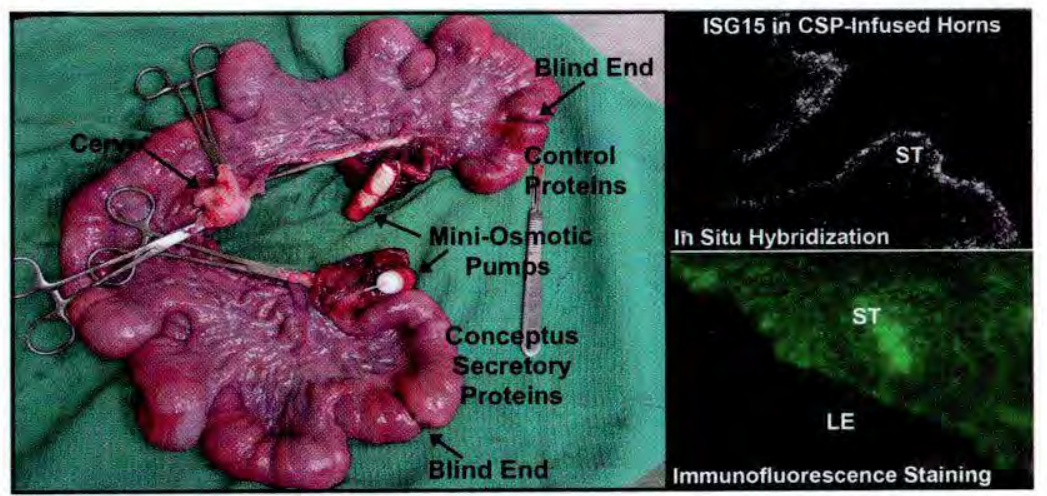

Fig. 3 Trophoblast IFNs increase expression of ISG15 within the endometrial stroma of domestic animals. A) In situ hybridization analyses for IFN-tau, IFN-gamma, and ISG15 mRNA in cross-sections of sheep and pig uterui and placentae. Corresponding brightfield and darkfield images from Day 15 pregnant $(\mathrm{P})$ sheep and pigs are shown. LE, luminal epithelium; ST, stroma; Tr, trophectoderm. Width of each field is $940 \mu \mathrm{m}$. B) Induction of ISG15 in pig endometrium by conceptus secretory proteins containing IFNG and IFND. Left panel: On Day 12 post-estrus pigs were surgically implanted with two indwelling ALZET osmotic pumps. For each pig, one uterine horn was infused by a pump filled with porcine serum albumin whereas the other uterine horn was infused by a pump filled with porcine conceptus secretory proteins (CSP) containing IFNs. Right panels: In situ hybridization and immunofluorescence detection of ISG15 within the stratum compactum stroma of horns infused with CSP. Horns infused with control serum albumin did not express ISG15 (data not shown). The rabbit polyclonal antibody against recombinant bovine ISG15 was kindly provided by Dr Thomas R. Hansen, Colorado State University.

et al. 1999, Chatterjee-Kishore et al. 2000, Stewart et al. 2002). Both Type I and Type II IFNs induce IRF1 expression (Floyd-Smith et al. 1999) which, in the reproductive tract of mice, has a role in placental development (Chatterjee-Kishore et al. 2000). In sheep, IRF1 expression increases in stroma and GE, but not in the LE during early pregnancy. Presumably, this is due to expression of IRF2, a potent transcriptional repressor of ISGs, that is constitutively expressed in the LE and increases during early pregnancy (Stewart et al. 2002). Pig and sheep endometria have similar patterns of expression for IRF1 and IRF2. IRF1 expression is upregulated in the stromal stratum compactum between Days 12 and 15 and remains through Day 25 of pregnancy (Joyce et al. 2007b). When pigs were implanted with mini-osmotic pumps that delivered conceptus secretory proteins (CSP) containing IFNs to the uterine horn (see Fig. 3) 
CSP increased IRFI in stroma, indicating upregulation of $I R F 1$ by conceptus IFNs (Joyce et al. 2007b). In contrast, IRF2 mRNA increased in LE after Day 12 in response to conceptus estrogen (Joyce et al. 2007b). The similar temporal and spatial patterns of expression for IRF1 and IRF2 in pigs and sheep support the idea that IRF2 represses expression of ISGs in the LE of pigs and perhaps mammals in general.

\section{Signal Transducer and Activator of Transcription (STAT) 1}

Cell-type specific induction of STAT1 expression in pig endometrium is differentially regulated by conceptus signals. Estrogen secretion by the conceptus on Day 12 increases STAT1 in the LE (Joyce et al. 2007a). Stromal induction of STAT1 correlates with secretion of IFND and IFNG by the conceptus, and intrauterine infusion of conceptus secretory proteins (see Fig. 3), which contain IFND and IFNG, increases STAT1 in a manner similar to that observed on Days 15-20 of pregnancy (Joyce et al. 2007a). STAT1 activation generally results in transcription of genes that are antiproliferative, proapoptotic and proinflammatory that could profoundly influence endometrial remodeling for implantation and placentation (van Boxel-Dezaire et al. 2006). Interestingly, although Type I IFNA and Type II IFNG each induce expression of largely non-overlapping sets of genes, they can also act in concert to reinforce physiological responses (Levy et al. 1990). This synergy has been demonstrated for induction of STAT1. Normally relatively non-responsive to IFNG, sequential treatment of cells with IFNG followed by IFNA results in higher magnitude ISG induction (Levy et al. 1990). In addition, co-treatment with IFNG and IFNA increases the magnitude and extends the period of ISG expression over IFNA alone (Decker et al. 1989). Clearly the pig may be unique among mammalian species studied. In pigs, combined conceptus IFND and IFNG may influence uterine physiology through cooperative induction of cytokine-specific transcription factors, such as STAT1, that allow reinforcement of effects of distinct cell-surface ligands while maintaining the specificities of the individual inducing IFNs in their ability to induce effects such as endometrial gene expression.

\section{Swine Leukocyte Antigens (SLA) and Beta 2 Microglobulin (B2M)}

MHC class I molecules (swine leukocyte antigens (SLAs) in pigs) and beta 2 microglobulin (B2M) are membrane glycoproteins that present peptide antigens to T cell receptors, and bind to inhibitory and activating receptors on natural killer cells and other leukocytes. They are involved in the discrimination of self from non-self by the immune system, and are essential to graft rejection. Downregulation of the expression of these classical MHC class I molecules and/or expression of nonclassical monomorphic MHC class I molecules by cells of the placenta benefit pregnancy (Hunt et al. 1987, Huddleston \& Schust 2004). Although known to be interferon response genes, $\mathrm{MHC}$ class I and B2M are absent from endometrial LE during the peri-implantation period (Choi et al. 2003, Joyce et al. 2008). In pigs, expression of classical SLA1, SLA2 and SLA3, non-classical SLA6, SLA7 and SLA8, and B2M increases in endometrial LE between Days 5 and 9 in response to progesterone, then decreases between Days 15 and 20 (Joyce et al. 2008). Downregulation of SLA class I and B2M expression in uterine LE, in coordination with a lack of expression of these genes by the placenta (Ramsoondar et al.1999), may be important for preventing fetal allograft rejection in species exhibiting epitheliochorial placentation. In contrast to the situation observed for $L E$, expression of SLAS and B2M increases in stromal cells by Day 15 of pregnancy in response to conceptus IFNs, and remains detectable through Day 40 (Joyce et al. 2008). Cell-type specific regulation of SLA and B2M expression by progesterone and IFNs suggests that placental secretions control expression of immune 
regulatory molecules on uterine cells to provide an immunologically favorable environment for survival of the fetal-placental semi-allograft.

\section{Conclusions and future directions}

Collectively, recent evidence from our laboratory and others suggests that pig conceptuses orchestrate precise temporal and spatial (cell-specific) changes in uterine gene expression through initial secretion of estrogens, followed by cytokines including IFNG and IFND. However, only a few differentially expressed genes have been investigated. Further, the pregnancy-specific role(s) of estrogen- and IFN-stimulated genes remains largely conjectural. Researchers in pig reproduction are challenged to incorporate new technologies including discovery-based microarray analyses to determine changes in global gene expression, adenovirus, morpholino and small interference RNAs to perform gain- and loss-of-function studies of specific endometrial and trophoblast genes, and state-of-the-art cell culture and imaging techniques necessary to delineate specific mechanistic functions of conceptus and uterine proteins.

\section{Acknowledgements}

This work was supported by National Research Initiative Competitive Grants nos. 2006-35203-17199 and 2008-35203-19120 from the USDA Cooperative State Research, Education, and Extension Service.

\section{References}

Bazer FW \& Thatcher WW 1977 Theory of maternal recognition of pregnancy in swine based on estrogen controlled endocrine versus exocrine secretion of prostaglandin $F 2 \alpha$ by the uterine endometrium. Prostaglandins 14 397-400.

Chatterjee-Kishore $M$, Wright $K L$, Ting JP \& Stark GR 2000 How Stat 1 mediates constitutive gene expression: a complex of unphosphorylated Stat 1 and IRF1 supports transcription of the L.MP2 gene. European Molecular Biology Journal $194111-4122$.

Choi, Y., G. A. Johnson, T. E. Spencer \& F. W. Bazer 2003. Pregnancy and interferon tau regulate major histocompatibility complex class 1 and beta2. microglobulin expression in the ovine uterus. Biology of Reproduction 68 1703-1710.

Cross JC \& Roberts RM 1989 Porcine conceptuses secrete an interferon during the preattachment period of early pregnancy. Biology of Reproduction $401109-1118$.

Decker T, Lew DJ, Cheng YS, Levy DE \& Darnell JEJ 1989 Interactions of alpha- and gamma-interferon in the transcriptional regulation of the gene encoding a guanylate-binding protein. European Molecular Biology lournal 8 2009-2014.

Flood PF 1974 Steroid-metabolizing enzymes in the early pig conceptus and in the related endometrium. Journal of Endocrinology $63413-414$.

Floyd-Smith G, Wang Q \& Sen G 1999 Transcriptional induction of the p69 isoform of 2',5'-oligoadenylate synthetase by interferon-beta and interferon-gamma involves three regulatory elements and interferonstimulated gene factor 3. Experimental Cell Research 246 138-147.

Geisert RD, Renegar RH, Thatcher WW, Roberts RM \& Bazer FW 1982a Establishment of pregnancy in the pig: I. Interrelationships between preimplantation development of the pig blastocyst and uterine endometrial secretions. Biology of Reproduction 27 925-939.

Geisert RD, Thatcher WW, Roberts RM \& Bazer FW 1982b Establishment of pregnancy in the pig: III. Endometrial secretory response to estradiol valerate administered on day 11 of the estrous cycle. Biology of Reproduction 27 957-965.

Harney JP \& Bazer FW 1989 Effect of porcine conceptus secretory proteins on interestrous interval and uterine secretion of prostaglandins. Biology of Reproduction 41 277-284.

Haas AL, Aherns P, Bright PM, Amhel H 1987 Interferon induces a 15-kilodalton protein exhibiting marked homology to ubiquitin. Journal of Biological Chemistry 262 11315-11323.

Hicks BA, Etter SI, Carnahan KG, Joyce MM, Assiri AA, Carling S), Kodali K, Johnson GA, Hansen TR, Mirando MA, Woods GL, Vandervall DK \& Ott TL 2003 Expression of the uterine $M x$ protein in cyclic and pregnant cows, gilts, and mares. Journal of Animal Science 81 1552-1561.

Huddleston H \& Schust D) 2004. Immune interactions 
at the maternal-fetal interface: a focus on antigen presentation. American Journal of Reproductive Immunology 51 283-289.

Hunt JS, Andrews GU \& Wood GW 1987. Normal trophoblasts resist induction of class I HLA. Journal of Immunology 138 2481-2487.

Johnson GA, Austin KJ, Van Kirk EA \& Hansen TR 1998 Pregnancy and interferon-tau induce conjugation of bovine ubiquitin cross-reactive protein to cytosolic uterine proteins. Biology of Reproduction $\mathbf{5 8}$ 898-904.

Johnson GA, Spencer TE, Hansen TR, Austin KJ, Burghardt RC \& Bazer FW 1999a Expression of the interferon-tau inducible ubiquitin cross-reactive protein in the ovine uterus. Biology of Reproduction 61 312-318.

Johnson GA, Austin KJ, Collins AM, Murdoch WJ \& Hansen TR 1999b Endometrial ISG17 mRNA and a related $m R N A$ are induced by interferon-tau and localized to glandular epithelial and stromal cells from pregnant cows. Endocrine 10 243-252.

Johnson GA, Burghardt RC, Bazer FW \& Spencer TE 2003 Minireview: Osteopontin: roles in implantation and placentation. Biology of Reproduction 69 1458-1471.

Joyce MM, White FJ, Burghardt RC, Muñiz I), Spencer TE, Bazer FW \& Johnson GA 2005 Interferon stimulated gene 15 conjugates to endometrial cytosolic proteins and is expressed at the uterine-placental interface throughout pregnancy in sheep. Endocrinology 146 675-684.

Joyce MM, Burghardt RC, Geisert RD, Burghardt JR, Hooper RN, Ross JW, Ashworth MD, Johnson GA 2007a Pig conceptuses secrete estrogen and interferons to differentially regulate uterine STAT 1 in a temporal and cell type-specific manner. Endocrinology 148 4420-4431.

Joyce MM, Burghardt JR, Burghardt RC, Hooper RN, Jaeger LA, Spencer TE, Bazer FW \& Johnson GA $2007 \mathrm{~b}$ Pig conceptuses increase uterine interferon regulatory factor-1 (IRF-1), but restrict expression to stroma through estrogen-induced IRF-2 in luminal epithelium. Biology of Reproduction 77 292-302.

Joyce MM, Burghardt JR, Burghardt RC, Hooper RN, Bazer FW \& Johnson GA 2008 Uterine major histocompatibility class 1 molecules and beta 2 microglobulin are regulated by progesterone and conceptus interferons during pig pregnancy. Journal of Immunology 181 2494-2505.

Ka H, Spencer TE, Johnson GA \& Bazer FW 2000 Keratinocyte growth factor: expression by endometrial epithelia in the porcine uterus. Biology of Reproduction 62 1772-1778.

Ka H, Al-Ramadan S, Erikson DW, Johnson GA, Burghardt RC, Spencer TE, Jaeger LA \& Bazer FW 2007 Regulation of Fibroblast Growth Factor 7 Expression in the Pig Uterine Endometrium by Progesterone and Estradiol. Biology of Reproduction 77 172-180.

Kraeling RR, Abbott B \& Hankinson O 1985 Inhibition of pregnancy with indomethacin in mature gilts and prepuberal gilts induced to ovulate. Biology of Reproduction 32 105-110.

Krzymowski T, Kotwica ] \& Stefanczyk-Krzymowska S 1990 uterine and ovarian countercurrent pathways in the control of ovarian function in the pig. Journal of Reproduction and Fertility Suppl. 40 179-191.

La Bonnardière $C$, Martinat-Botté $F$, Terqui $M$, Lefèvre $F$, Zouari K, Martal J \& Bazer FW 1991 Production of two species of interferon by Large White and Meishan pig conceptuses during the peri-attachment period. Journal of Reproduction and Fertility 91 469-478.

Lefèvre F, Guillomot $M$, D'Andrea S, Battegay S \& La Bonnardière C 1998 Interferon-delta: the first member of a novel type I interferon family. Biochimie $80779-788$.

Levy DE, Lew DJ, Decker T, Kessler DS \& Darnell JEJ 1990 Synergistic interaction between interferon-alpha and interferon-gamma through induced synthesis of one subunit of the transcription factor ISGF3. European Molecular Biology lournal 9 1105-1111.

Madsen KL, Tavernini MM, Yachimec C, Mendrick DL, Alfonso PJ, Buergin M, Olsen HS \& Antonaccio MJ, Thomson AB, Fedorak RN 1998 Stanniocalcin: a novel protein regulating calcium and phosphate transport across mammalian intestine. American Journal of Physiology 274 G96-G102.

Mirando MA, Harney JP, Beers S, Pontzer CH, Torres BA, Johnson HM \& Bazer FW 1990 Onset of secretion of proteins with antiviral activity by pig conceptuses. Journal of Reproduction and Fertility 88 197-203.

Naivar KA, Ward SK, Austin KJ, Moore DW \& Hansen TR 1995 Secretion of bovine uterine proteins in response to type 1 interferons. Biology of Reproduction $\mathbf{5 2}$ 848-854.

Ramsoondar J, Christopherson RJ, Guilbert LJ, Dixon WT, Ghahary A, Ellis S, Wegmann TG \& Piedrahita IA 1999. Lack of class 1 major histocompatibility antigens on trophoblast of periimplantation blastocysts and term placenta in the pig. Biology of Reproduction 60 387-397.

Rempel LA, Austin KJ, Ritchie KJ, Yan M, Shen M, Zhang D-E, Henkes LE \& Hansen TR 2007 Ubp43 gene expression is required for normal Isg15 expression and fetal development. Reproductive Biology and Endocrinology 5 1-15.

Ross IW, Ashworth MD, White FJ, Johnson GA, Aoubi PJ, DeSilva UE, Whitworth KM, Green JA, Prather RS \& Geisert RD 2007 Premature estrogen exposure alters endometrial gene expression to disrupt pregnancy in the pig. Endocrinology 148 4761-4773.

So H, Kim M, Choi Y, Lee CK \& Ka H 2008 Analysis of lysophosphatidic acid (LPA receptor and LPA-induced endometrial prostaglandin-endoperoxide synthase 2 expression in the porcine uterus. Endocrinology 149 6166-6175.

Song G, Bazer FW, Wagner GF \& Spencer TE 2006 Stanniocalcin (STC) in the endometrial glands of the ovine uterus: regulation by progesterone and placental hormones. Biology of Reproduction 74 913-922.

Song G, Dunlap KA, Kim J, Bailey DW, Spencer TE, 
Burghardt RC, Johnson GA \& Bazer FW 2009 Stanniocalcin 1 is a Luminal Epithelial Marker for Implantation in Pigs Regulated by Progesterone and Estrogen. Endocrinology 150 936-945.

Spencer TE, Johnson GA, Bazer FW, Burghardt RC \& Palmarini M 2007 Pregnancy recognition and conceptus implantation in domestic ruminants: roles of progesterone, interferons and endogenous retroviruses. Reproduction Fertility \& Development 19 65-78.

Stasko SE, DiMattia GE \& Wagner GF 2001 Dynamic changes in stanniocalcin gene expression in the mouse uterus during early implantation. Molecular Cell Endocrinology 174 145-149.

Stewart MD, Choi Y, Johnson GA, Yu-Lee L-Y, Bazer FW \& Spencer TE 2002 Roles of Stat1, Stat 2 and interferon regulatory factor-9 (IRF-9) in interferon tau regulation of IRF-1. Biology of Reproduction 66 393-400.

van Boxel-Dezaire AHH, Rani MRS \& Stark GR 2006 Complex modulation of cell type-specific signaling in response to type 1 interferons. Immunity $\mathbf{2 5}$ 361-372.

Wagner GF, Hampong M, Park CM \& Copp DH 1986 Purification, characterization, and bioassay of teleocalcin, a glycoprotein from salmon corpuscles of Stannius. General Comparative Endocrinology 63 481-491.

Wasielak M, Glowacz M, Kaminska K, Waclawik A \& Bogacki M 2008 The influence of embryo presence on prostaglandin syntesis and prostaglandin E2 and $\mathrm{F} 2 \alpha$ content in corpora lutea during periimplantation period in the pig. Molecular Reproduction and Development 75 1208-1216.

White FJ, Ross JW, Joyce MM, Geisert RD, Burghardt RC \& Johnson GA 2005 Steroid regulation of cell specific secreted phosphoprotein 1 (osteopontin) expression in the pregnant porcine uterus. Biology of Reproduction 73 1294-130147.

Wilkinson KD 2000 Ubiquitination and deubiquitination: targeting of proteins for degradation by the proteasome. Cell and Developmental Biology 11 141-148.

Ye X, Hama K, Contos IJ, Anliker B, Inoue A, Skinner MK, Suzuki H, Amano T, Kennedy G, Arai H \& Aoki I 2005 LPA3-meditated lysophosphatidic acid signaling in embryo implantation and spacing. Nature 435 34-35

Ziecik AJ, Waclawik A \& Bogacki M 2008 Conceptus signals for establishment and maintenance of pregnancy in pigs - lipid signaling system. Experimental Clinical Endocrinology and Diabetes 116 443-449. 